\title{
Microstructural evaluation of Bi-Ag and Bi-Sb lead-free high-temperature solder candidates on copper substrate with multiple reflow number
}

\begin{abstract}
An impetus has been provided towards the development of lead-free solders by worldwide environmental legislation that banned the use of lead in solders due to the lead toxicity. This study focus on $\mathrm{Bi}-\mathrm{Ag}$ and $\mathrm{Bi}-\mathrm{Sb}$ solder alloys, in compositions from 1.5 to $5 \mathrm{wt} \% \mathrm{Ag}$ and $\mathrm{Sb}$. The effects of $\mathrm{Ag}$ and $\mathrm{Sb}$ amount, and reflow number on the microstructure and morphology of solder bulk were analysed by optical microscope and scanning electron microscope-energy dispersive X-ray. Based on the results, the grain boundary grooving was observed in all samples except $\mathrm{Bi}-5 \mathrm{Sb}$ in all three reflows. Metallurgical and chemical reaction between interface and solders were found in Bi-5Sb solder alloys in different reflow numbers which lead to appearance of $\mathrm{Cu} 3 \mathrm{Sb}$ intermetallic compound layer at the interface. Reflow numbers had a significant effect on the size of $\mathrm{Cu}$-rich phase. Also it was observed that, with increasing reflow number $\mathrm{Bi}-\mathrm{Cu}$ phase found in $\mathrm{Bi}-2.5 \mathrm{Sb}$ solder dissolves into the solder bulk.
\end{abstract}

Keyword: $\mathrm{Bi}-\mathrm{Ag}$ solder alloy; Bi-Sb solder alloy; Grain boundary grooving; Intermetallic compound (IMC); Lead-free solder; Multiple reflow number 